\title{
The GIn/Gln genotype of XPD codon 751 as a genetic marker for melanoma risk and Lys/Gln as an important predictor for melanoma progression: A case control study in the Swedish population
}

\author{
KHADIJA KERTAT ${ }^{1}$, INGER ROSDAHL ${ }^{1}$, XIAO-FENG SUN ${ }^{2}$, INGRID SYNNERSTAD ${ }^{1}$ and HONG ZHANG ${ }^{1,3}$ \\ Divisions of ${ }^{1}$ Dermatology and ${ }^{2}$ Oncology, Department of Experimental and Clinical Medicine, Linköping \\ University, SE-581 85 Linköping; ${ }^{3}$ School of Life Sciences, University of Skövde, SE-541 28 Skövde, Sweden
}

Received October 3, 2007; Accepted January 17, 2008

\begin{abstract}
The Xeroderma pigmentosum complementation group D (XPD) is a critical protein in the nucleotide excision repair system for DNA damage. Genetic variations in XPD exert an important effect on the capacity of DNA repair. In this study, we examined Lys751Gln polymorphism at the XPD gene in 244 melanoma patients and 251 healthy individuals (as controls) from the south-eastern region of Sweden. The associations of polymorphism with melanoma risk, as well as with melanoma features and pigment phenotypes of the melanoma patients were analysed. DNA was extracted from the mononuclear cells of venous blood of the melanoma patients and controls. XPD codon 751 was genotyped by the PCR restriction fragment length polymorphism technique. Results showed that there was no difference in the distribution of the XPD codon 751 genotypes between the melanoma patients and healthy controls. However, the Gln/Gln genotype was found to be associated with melanoma risk in the male population. Furthermore, the frequency of the Gln/Gln genotype was significantly higher in the early stages of melanomas, whereas Lys/Gln was more frequent in the later stages and in the patients with melanoma located on intermittently UVexposed areas. No correlations between the polymorphisms and phenotypes of the patients were found. In conclusion, $\mathrm{Gln} / \mathrm{Gln}$ was a useful genetic marker for melanoma risk in the males, while Lys/Gln was an important predictor for melanoma progression.
\end{abstract}

\section{Introduction}

Cutaneous melanoma is the most lethal skin malignancy (1) with a markedly increasing incidence among fair-skinned

Correspondence to: Dr Hong Zhang, School of Life Sciences, University of Skövde, SE-541 28 Skövde, Sweden

E-mail: hong.zhang@his.se

Key words: xeroderma pigmentosum complementation group D, polymorphism, risk, progression, melanoma populations in Western countries over the last decades $(2,3)$. There are plenty of risk factors which have been found to be linked to melanoma, including genetic predispositions, such as family background with various genetic alterations (4) and pigment phenotypes, such as skin types and eye and hair color (5).

Melanoma develops in a multi-step process with initiation, promotion, transformation and metastasis. During melanoma progression the number of alterations in genomic DNA increases (6). It has been proven that UV radiation from sunlight as a complete carcinogen causes skin cancers without additional initiators or promoters (7). UVA and UVB differentially induce damage in human skin melanocytes, resulting in melanoma in various ways (8). The nucleotide excision repair system has been found to remove UVinduced DNA damage in human cells (9), and the key protein in this repair pathway is the xeroderma pigmentosum complementation group D (XPD) or excision repair crosscomplementing group 2 (10). The XPD gene is located on chromosome 19 and codes for an $86.9 \mathrm{kDa}$ protein with 761 amino acids. In codon 751 of the XPD gene, lysine has changed to glutamine (Lys751Gln). This polymorphism with the A-C transition results in a total change in the electronic configuration and functions of the protein. Since this amino acid is situated in the domain with an important function, the polymorphism in this site can be of importance (11).

Since the XPD gene has been shown to be involved in melanoma risk, it is of interest to evaluate whether these alterations in the polymorphisms of the XPD gene play an essential role for melanoma risk, and progression. We examined the frequency of Lys751Gln polymorphism in the XPD gene in melanoma patients and the healthy controls from the south-eastern region of Sweden. The association of the polymorphism with clinicopathological characteristics as well as pigmented phenotypes within the patient groups was also analysed.

\section{Materials and methods}

Melanoma patients and healthy individuals. This study was approved by the regional ethics committee at the Linköping 


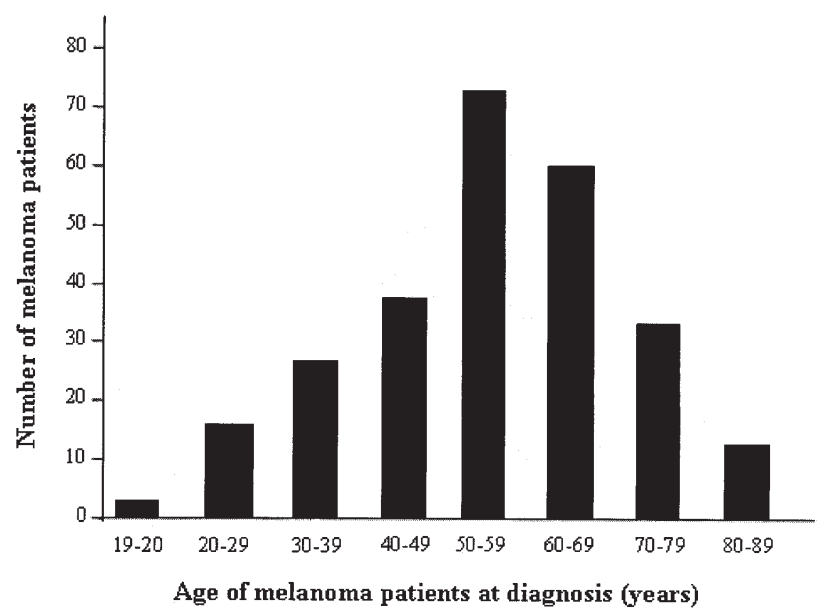

Figure 1. The age distributions at the melanoma diagnosis in the melanoma patients.

University, Linköping, Sweden. All patients participating in this study were informed about the study details and signed a written consent.

There were 244 melanoma patients (125 females and 119 males) from the south-eastern region of Sweden. The patients were diagnosed with primary melanoma at the University Hospital of Linköping, Norrköping Hospital and Kalmar Hospital, Sweden. The age of the melanoma patients at the time of diagnosis was from 18 to 87 years with a mean age of 54.9. Data were unavailable for three patients (Fig. 1). Clinicopathological features of the melanomas and phenotypes of the melanoma patients are presented in Table I. Tumour locations were noted by using a schematic chart as previously described (12), and classified into chronically, intermittently or rarely UV-exposed areas. The histopathological types of melanomas were taken from the pathology records from the categories: melanoma in situ, superficial spreading (SSM), nodular (NM), lentigo malignant (LMM) and acro-lentiginous melanoma (ALM). Breslow thickness was divided into $<0.75,0.75-1.5$ and $>1.5 \mathrm{~mm}$, and the Clark level was scaled as I-IV (Table I). Skin types were classified into four groups (I-IV) as previously described (13). Due to the limited number of melanoma cases, we grouped I and II as sensitive skin type and III and IV as less sensitive. The eye color of the melanoma patients was classified into blue/ green and brown/mixed and hair colour into blond/red and brown/black (Table I).

Caucasian healthy controls consisted of 251 individuals (120 males and 131 females). The age of the control individuals at the time of DNA collection was 20-79 (mean: 52.7 years) from the same geographic region as the melanoma patients and with age and gender matched to the melanoma patients. The controls were representative of the general population (shown by the Hardy-Weinberg equilibrium).

DNA extraction. After a short interview, 8-10 $\mathrm{ml}$ of venous blood from each melanoma patient was collected into anticoagulant tubes. DNA was extracted from the mononuclear cells of the blood samples according to the manufacturer's instructions by using the DNA blood maxi kit from Qiagen (Hilden, Germany). DNA concentration was measured by
Table I. The tumour characteristics and pigment phenotypes of melanoma patients.

\begin{tabular}{lc}
\hline Pathological variables and phenotypes & Patients $(\%)$ \\
\hline Histopathological type & \\
Superficial spreading melanoma (SSM) & $150(60.2)$ \\
Nodular melanoma (NM) & $48(19.3)$ \\
Lentigo malignant melanoma (LMM) & $10(4.0)$ \\
Acro-lentiginous melanoma (ALM) & $2(0.8)$ \\
Melanoma in situ & $22(8.8)$ \\
Breslow thickness (mm) & \\
$<0.75$ & $65(26.1)$ \\
$0.75-1.5$ & $73(29.3)$ \\
$>1.5$ & $68(27.3)$ \\
Clark level & \\
I+ II & $87(34.9)$ \\
III + IV & $134(53.8)$ \\
Skin type & \\
I+II & $139(56.2)$ \\
III+IV & $105(42.6)$ \\
Eye color & \\
Blue + green & \\
Brown + mixed & $203(81.9)$ \\
Hair color & $41(16.9)$ \\
Blond + red & \\
Brown + black & \\
\hline & \\
&
\end{tabular}

UV spectrometry with a NanoDrop ND-1000 Spectrophotometer (Nanodrop Technologies, Wilmington, DE, USA), and working solutions $(50 \mathrm{ng} / \mu \mathrm{l})$ were prepared in DNA buffer from Qiagen and kept at $4^{\circ} \mathrm{C}$.

The genotyping of XPD codon 751 by PCR-restriction fragment length polymorphism (RFLP). The genome of codon 751 of the XPD gene was amplified by PCR with a forward primer of 5'-GCCCGCTCTGGATTATACG-3' and reverse primer of 5'-CTATCATCTCCTGGCCCCC-3' to produce a $436 \mathrm{bp}$ fragment (14-16). The PCR reactions were carried out in $20 \mu 1$ reaction containing 50-70 ng genomic DNA, $200 \mu \mathrm{M}$ of dNTP mix (Invitrogen Life Technologies, Carlsbad, CA, USA), $2.0 \mathrm{mM} \mathrm{MgCl}_{2}$ (Promega, Madison, WI, USA), 1X PCR buffer $(500 \mathrm{mM} \mathrm{KCl}, 100 \mathrm{mM}$ Tris- $\mathrm{HCl}, 1 \%$ Triton X-100, pH 9.0 at $25^{\circ} \mathrm{C}$ ), $3 \mathrm{U}$ Taq DNA polymerase (Promega) and $0.2 \mu \mathrm{M}$ of each primer (Invitrogen). The samples were amplified in a thermal cycler (GeneAmp PCR System 2700, Applied Biosystems, Foster City, CA, USA) with an annealing temperature of $60^{\circ} \mathrm{C}$ for $30 \mathrm{sec}$ and for 30 cycles. The genotype of polymorphism at XPD codon 751 was determined by a restriction enzyme Pst (New England Biolabs, Beverly, MA, USA). In brief, the PCR product (15 $\mu \mathrm{l})$ was mixed with $5 \mu \mathrm{l}$ (20 U) PstI, 1 X NEBuffer, $\mathrm{NaCl}$, Tris- $\mathrm{HCl}, \mathrm{MgCl}_{2}$, DTT and $100 \mu \mathrm{g} / \mathrm{ml}$ bovine serum albumin at $\mathrm{pH} 7.9$ (New England Biolabs), and incubated at $37^{\circ} \mathrm{C}$ for $24 \mathrm{~h}$. The digested products 


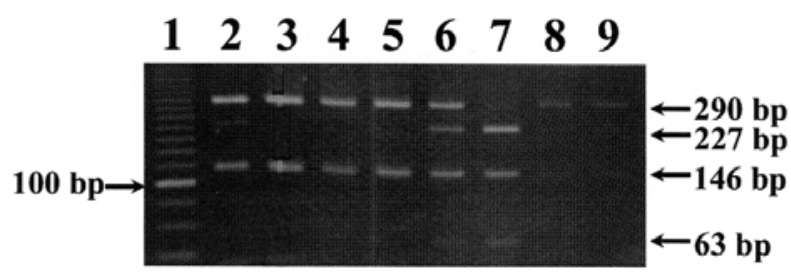

Figure 2. The genotyping of XPD codon 751 in melanoma patients and healthy controls. The genotypes were examined by PCR-RFLP and visualized with 3.5\% agarose gel. Lane 1: 25 bp DNA ladder; lanes 2, 6, 8 and 9: heterozygous Lys/Gln (290, 227, 146 and 63 bp fragments); lanes 3, 4 and 5: wild-type Lys/Lys (290 and 146 bp fragments) and lane 7: polymorphic homozygous Gln/Gln (227, 146 and 63 bp fragments).

were then resolved in 3.5\% agarose gel (Invitrogen Life Technologies Paisley, Scotland) containing $0.2 \mathrm{mg} / \mathrm{ml}$ ethidium bromide (150 V for 50-60 min). There was one cleavage site for PstI for the homozygous wild-type allele (Lys/Lys) with DNA fragments of 290 and 146 bp and a polymorphic allele $(\mathrm{Gln} / \mathrm{Gln})$ with three fragments. The A-C transition in the polymorphic allele generated an extra recognition site for the restriction enzyme within the $290 \mathrm{bp}$ fragment in the wild-type allele. This cleavage gave rise to two fragments of 227 and $63 \mathrm{bp}$ and the XPD $751 \mathrm{Gln} / \mathrm{Gln}$ polymorphic genotype showed the 63, 146 and 227 bp fragments. The heterozygote genotype (Lys/Gln) showed four bands at 63, 146, 227 and 290 bp.

Statistical analysis. The $\chi^{2}$-test was used to estimate differences in the frequency of the genotype in XPD codon 751 between melanoma patients and the healthy controls, and the differences between the polymorphisms and clinicopathological features and phenotypes of melanoma patients. P-values were two-sided and values $<0.05$ were considered as statistically significant.

\section{Results}

Polymorphisms in XPD codon 751 were examined by the PCR-RFLP technique in 244 melanoma patients and 251 healthy individuals. The PCR product corresponding to the XPD codon 751 was represented with a specific 436 bp band and cleaved by the enzyme PstI as shown in Fig. 2.

XPD polymorphisms in melanoma risk. Three different genotypes in XPD codon 751 were seen in the melanoma patients and healthy individuals. As shown in Table II, we did not find a significant difference in the distribution of these genotypes between the melanoma patients and controls. We further analysed the association of the XPD codon 751 polymorphism either in males or in females, respectively. In the males, the frequency of Gln/Gln genotype was found to be higher in melanoma patients $(26.5 \%)$ than the controls (13.7\%) $(\mathrm{P}=0.02)$. However, the frequency of the heterozygous form was lower in the patients $(41.0 \%)$ than in the controls $(56.5 \%)$. There was a significant difference between the Lys/Gln and Gln/Gln genotypes $(\mathrm{P}=0.009)$, but not in the combinations of Lys/Lys vs. Lys/Gln $(\mathrm{P}=0.23)$ and Lys/Lys vs. $\mathrm{Gln} / \mathrm{Gln}(\mathrm{P}=0.18)$. However, in the females, we did not find such a significant difference (Table II).
Table II. The distribution of the XPD codon 751 genotypes in melanoma patients and healthy controls.

\begin{tabular}{ccccc}
\hline Variable & Lys/Lys & Lys/GIn & GIn/GIn & P-value \\
\hline Overall & & & & 0.55 \\
Patient & $78(32.4)$ & $122(50.6)$ & $41(17.0)$ & \\
Control & $82(32.7)$ & $135(53.8)$ & $34(13.5)$ & \\
Male & & & & 0.02 \\
Patient & $38(32.5)$ & $48(41.0)$ & $31(26.5)$ & \\
Control & $37(29.8)$ & $70(56.5)$ & $17(17.8)$ & \\
Female & & & & 0.76 \\
Patient & $38(31.7)$ & $67(55.8)$ & $15(12.5)$ & \\
Control & $45(35.4)$ & $65(51.2)$ & $17(13.7)$ & \\
\hline
\end{tabular}

Table III. The distribution of the XPD codon 751 genotypes in melanoma patients corresponding to age and gender.

\begin{tabular}{lcccc}
\hline Variable & Lys/Lys & Lys/GIn & GIn/GIn & P-value \\
\hline $\begin{array}{l}\text { Age } \\
\text { (year) }\end{array}$ & & & & \\
$\quad \leq 50$ & $26(31.0)$ & $46(54.8)$ & $12(14.3)$ & 0.69 \\
$>50$ & $51(33.1)$ & $76(49.4)$ & $27(17.5)$ & \\
Gender & & & & 0.01 \\
$\quad$ Male & $38(32.5)$ & $48(41.0)$ & $31(26.5)$ & \\
Female & $28(31.7)$ & $67(55.8)$ & $15(12.5)$ & \\
\hline
\end{tabular}

XPD polymorphisms in melanoma patients. As shown in Table III, XPD codon 751 genotypes were analysed in subgroups of melanoma patients with a cut-off age of 50 years as well as two extreme groups with younger $(<35$ years) and older patients ( $>65$ years). No significant differences in the distributions of the XPD polymorphisms between these subgroups of different ages were found. Furthermore, the frequency of the Gln/Gln genotype was analysed between male and female patients, and the genotype was found to be significantly higher in the males $(26.5 \%)$ than that in the females $(12.5 \%)$. However, the heterozygous genotype was less frequent in the males $(41.0 \%)$ than in females $(55.8 \%)$ $(\mathrm{P}=0.01)$.

XPD polymorphisms with clinicopathological characteristics. The associations of the XPD codon 751 genotypes with clinicopathological characteristics including histopathological type, Breslow thickness, Clark level and the tumour site were also evaluated. We did not find statistical significance in the genotype distribution within the histopathological types. There was also no difference in frequency between SSM (60.2\%) and NM (19.3\%). The frequency of the Gln/Gln genotype gradually decreased along with the increased Breslow thickness from $22.7 \%$ in $<0.75 \mathrm{~mm}$ melanoma, $15.2 \%$ in $0.75-1.5 \mathrm{~mm}$ tumour and $10.4 \%$ in $>1.5 \mathrm{~mm}$ ones, although this tendency was not statistically significant 
Table IV. The distribution of the XPD codon 751 genotypes in relation to clinicopathological features of melanoma patients.

\begin{tabular}{lcrr}
\hline Variable & Lys/Lys & Lys/GIn & GIn/GIn \\
\hline $\begin{array}{l}\text { Histopathological (type) } \\
\text { SSM }\end{array}$ & $47(31.8)$ & $79(53.4)$ & $22(14.9)$ \\
NM & $16(34.0)$ & $24(51.1)$ & $7(14.9)$ \\
Breslow thickness (mm) & & & \\
$<0.75$ & $21(31.8)$ & $30(45.5)$ & $15(22.7)$ \\
$0.75-1.5$ & $23(34.8)$ & $33(50.0)$ & $7(15.2)$ \\
$>1.5$ & $18(26.9)$ & $42(62.7)$ & $0.95)$ \\
Clark level & & & $18(22.2)$ \\
I+II & $21(25.9)$ & $42(51.9)$ & $12(9.20)$ \\
III+IV & $47(36.2)$ & $71(54.6)$ & 0.02 \\
\hline
\end{tabular}

Table V. The distribution of the XPD codon 751 genotypes in relation to pigment-related phenotypes of melanoma patients.

\begin{tabular}{|c|c|c|c|c|}
\hline Variable & Lys/Lys & Lys/GIn & GIn/GIn & $\mathrm{P}$-value \\
\hline Skin type & & & & 0.87 \\
\hline $\mathrm{I}+\mathrm{II}$ & $43(31.4)$ & $69(50.4)$ & $25(18.2)$ & \\
\hline III+IV & $34(33.7)$ & $51(50.5)$ & $16(15.8)$ & \\
\hline Eye color & & & & 0.14 \\
\hline Blue + green & $61(31.0)$ & 98 (49.7) & $38(19.3)$ & \\
\hline Brown + black & $17(41.5)$ & $21(51.2)$ & $3(7.30)$ & \\
\hline Hair color & & & & 0.30 \\
\hline Blond + red & $61(30.8)$ & $102(51.5)$ & $35(17.7)$ & \\
\hline Dark + black & $17(43.6)$ & $16(41.0)$ & $6(15.4)$ & \\
\hline
\end{tabular}

$(\mathrm{P}=0.21)$. We found that the frequency of Lys/Gln was higher and lower in Gln/ Gln genotypes when comparing the $<0.75 \mathrm{~mm}$ tumours with the $>1.5 \mathrm{~mm}(\mathrm{P}=0.05$, Table IV). Notably, the frequency of the Gln/Gln genotype was found to be increased in Clark levels I and II (22.2\%) as compared to Clark III and IV melanomas $(9.2 \%, \mathrm{P}=0.02$, Table IV). However, the frequency of the Lys/Gln genotype was higher in the melanoma patients in Clark levels III and IV than those in Clark I and II.

The distributions of the Lys/Gln and Gln/Gln genotypes were analysed in the melanoma patients with tumours located on sites rarely exposed to UV light compared to those on intermittently exposed sites. The polymorphic homozygote genotype was found to be more frequent in melanomas on the rarely exposed sites (48.2\%) than those on the intermittently exposed sites $(25.6 \%)$. However, the frequency of the heterozygous form (Lys/Gln or Gln/Gln) was higher in the patients with melanomas on the intermittently exposed areas than the rarely exposed ones (74.4 and 51.8\%, respectively, $\mathrm{P}=0.03$ ).

XPD polymorphisms with pigment phenotypes of melanoma patients. We further analysed the association of the XPD codon 751 genotypes with pigment phenotypes of the melanoma patients (Table V). A higher frequency of the Gln/Gln genotype (19.3\%) was found in the patients with blue or green eyes as compared to those with brown or black eyes $(7.3 \%)$. A similar trend was observed concerning hair colour and skin type (17.7\% in blond- and red-haired patients compared to $15.4 \%$ dark-haired ones and $18.2 \%$ in fair-skinned patients and $15.8 \%$ in dark-skinned ones). The trend still remained when melanoma patients were divided into sensitive (blue/green eyes, fair hair and skin type I/II), and non-sensitive (brown/black eyes, dark/black hair and skin type III/IV) groups (Table V).

\section{Discussion}

The XPD protein is important in DNA damage repair. Various polymorphisms at codon 751 of the XPD gene have been indicated as having functional relevance due to a shift of amino acid substitution from lysine to glutamine (17). In this study, we examined the codon 751 polymorphism in the XPD gene in melanoma patients and healthy individuals from the south-eastern region of Sweden. Based on our knowledge, this was the first study in a large series of Swedish melanoma patients and healthy individuals as controls. Controversial results have been reported concerning these polymorphisms and melanoma risk. Baccarelli and colleagues have reported that the XPD $751 \mathrm{Gln} / \mathrm{Gln}$ genotype is related to melanoma risk in the patients $>50$ years (18). Winsey and co-workers 
found that there is no association of polymorphism in XPD codon 751 with melanoma risk (19). However, Han and his colleagues observed an inverse relation of the polymorphisms with the risk of melanoma (20). A large cohort study recently showed an association of the genotype in XPD codon 751 Gln/Gln with melanoma risk, especially in patients $<30$ years (21). In the present Swedish study, we did not find the association of the XPD codon 751 polymorphisms with melanoma risk. Taken together, the role of the XPD codon 751 polymorphisms have yet to be clarified. Further investigations are needed to understand the mechanisms behind the functions of XPD codon 751 polymorphisms in melanoma.

Notably, we found a strong correlation of the Gln/Gln genotype with melanoma risk in the males $(\mathrm{P}=0.009)$. The frequency of codon 751 of the XPD gene was significantly higher in the males compared to females $(\mathrm{P}=0.006)$, indicating that this polymorphism played an important role in the predisposition to melanoma with regard to the male gender, which was in agreement with an earlier report showing the survival advantage for female patients with primary melanoma (22). Based on these findings, we further speculated about the interaction(s) between the XPD and gender-related gene, or the gene products. However, further investigations are needed to illustrate the pathways between the interactions more accurately.

We analysed the association of the XPD codon 751 polymorphism with Breslow thickness and Clark levels. The frequency of the Gln/Gln genotype was higher in patients with thin tumours $(<0.75 \mathrm{~mm})$ and in the earlier Clark level (I and II) melanomas. The heterozygous form of the Gln/Gln genotype was more frequent in melanomas with a Breslow thickness of $>1.5 \mathrm{~mm}$, and the Clark level III/IV, indicating that the XPD polymorphic genotype was a predictor for the early stages of melanoma.

Intermittent sun exposure has been repeatedly reported to increase melanoma risk (2). In the present study, we showed that the patients with melanomas on the rarely UV-exposed sites had a higher frequency of the XPD genotype versus those on the intermittently exposed sites. The frequency of the XPD genotype was higher in patients with tumours located on the intermittently exposed sites compared to the rarely exposed sites. These results indicated that the Lys/Gln genotype was a risk factor for individuals who were exposed intensely and irregularly to the sunlight. Moreover, we found no associations of clinicopathological features of melanoma, tumour location and pigment phenotypes in the melanoma patients. In the case-control study, the frequency of the $\mathrm{Gln} / \mathrm{Gln}$ genotype was found to be higher in patients with a low-tanning ability skin type as compared to tumour-free individuals. However, no association has been found concerning eye colour (19).

In conclusion, the Gln/Gln genotype of XPD codon 751 was a useful genetic marker for melanoma risk in males and Lys/Gln was important in predicting tumour progression.

\section{Acknowledgements}

The authors are grateful to Katarina Holmdahl-Källen, Kenneth Lagmo Eva Niklasson and Mona-Lisa Sandh for kindly collecting blood samples. The study was supported by research grants from the Cancer and Allergy Foundation, Edward Welander Foundation and Health Research Council in the south-east of Sweden.

\section{References}

1. Rager EL, Bridgeford EP and Ollila DW: Cutaneous melanoma: update on prevention, screening, diagnosis, and treatment. Am Fam Physician 72: 269-276, 2005.

2. Bressac-de-Paillerets B, Avril MF, Chompret A and Demenai F: Genetic and environmental factors in cutaneous malignant melanoma. Biochimie 84: 67-74, 2002.

3. Slominski A, Wortsman J, Carlson AJ, Matsuoka LY, Balch CM and Mihm MC: Malignant melanoma. Arch Pathol Lab Med 125: 1295-1306, 2001 .

4. Oliveria SA, Saraiya M, Heneghan MK and Jorgensen C: Sun exposure and risk of melanoma. Arch Dis Chil 91: 131-138, 2006.

5. Gandini S, Sera F, Cattaruza MS, Pasquini P, Zanetti R, Masini C, et al: Meta-analysis of risk factors for cutaneous melanoma: III. Family history, actinic damage and phenotypic factors. Eur J Cancer 41: 2040-2059, 2005.

6. Wang SQ, Setlow R, Berwick M, Polsky D, Marghoob AA, Kopf AW, et al: Ultraviolet A and melanoma: a review. J Am Acad Dermatol 44: 837-846, 2001

7. Melnikova VO and Ananthaswamy HN: Cellular and molecular events leading to the development of skin cancer. Mutation Res 571: 91-106, 2005.

8. Zhang $\mathrm{H}$ and Rosdahl I: Ultraviolet A and B differently induce intracellular protein expression in human skin melanocytes: a speculation of separate pathways in initiation of melanoma. Carcinogenesis 24: 1929-1934, 2003.

9. Sancar A: DNA repair in humans. Ann Rev Genet 29: 69-105, 1995.

10. Benhamou S and Sarasin A: ERCC2/XPD gene polymorphisms and cancer risk. Mutagenesis 17: 463-469, 2002.

11. Coin F, Marinoni JC, Rodolfo C, Fribourg S, Pedrini AM and Egly JM: Mutations in the XPD helicase gene result in XP and TTD phenotypes, preventing interaction between XPD and the p44 subunit of TFIIH. Nat Genet 20: 184-188, 1998.

12. Stierner U, Augustsson A, Rosdahl I and Suurküla M: Regional distribution of common and dysplastic naevi in relation to melanoma site and sun exposure. A case-control study. Melanoma Res 1: 367-375, 1991 .

13. Melski JW, Tanenbaum L, Parrish JA, Fitzpatrick TB and Bleich HL: Oral methoxsalen photochemistry for the treatment of psoriasis: a cooperative clinical trial. J Invest Dermatol 68: 328-335, 1977.

14. Qiao Y, Spitz MR, Shen H, Guo Z, Shete S, Hedayati M, et al: Modulation of repair of ultraviolet damage in the host-cell reactivation assay by polymorphic XPC and XPD/ERCC2 genotypes. Carcinogenesis 23: 295-299, 2002.

15. Spitz MR, Wu X, Wang Y, Wang L, Shete S, Amos CI, et al: Modulation of nucleotide excision repair capacity by XPD polymorphisms in lung cancer patients. Cancer Res 61: 1354-1357, 2001.

16. Yu HP, Wang XL, Sun X, Su YH, Wang YJ, Lu B, et al: Polymorphisms in the DNA repair gene XPD and susceptibility to esophageal squamous cell carcinoma. Cancer Genet and Cytogenet 154: 10-15, 2004.

17. Clarkson SG and Wood RD: Polymorphisms in the human XPD (ERCC2) gene, DNA repair capacity and cancer susceptibility: an appraisal. DNA Repair 4: 1068-1074, 2005.

18. Baccarelli A, Calista D, Minghetti P, Marinelli B, Albetti B, Tseng T, et al: XPD gene polymorphism and host characteristics in the association with cutaneous malignant melanoma risk. Br J Cancer 90: 497-502, 2004.

19. Winsey SL, Haldar NA, Marsh HP, Bunce M, Marshall, SE, Harris AL, et al: A variant within the DNA repair gene XRCC3 is associated with the development of melanoma skin cancer. Cancer Res 60: 5612-5616, 2000.

20. Han J, Colditz GA, Liu JS and Hunter DJ: Genetic variation in XPD, sun exposure, and risk of skin cancer. Cancer Epidemiol Biomarkers Prev 14: 1539-1544, 2005.

21. Millikan RC, Hummer A, Begg C, Player J, De Cotret AR, Winkel S, et al: Polymorphisms in nucleotide excision repair genes and risk of multiple primary melanoma: the genes environment and melanoma study. Carcinogenesis 27: 610-618, 2006.

22. Miller JG and Mac Neil SM: Gender and cutaneous melanoma. Br J Dermatol 1136: 657-665, 1997. 